\title{
Methane emissions of manure from dairy cows fed red clover- or corn silage-based diets supplemented with linseed oil
}

\section{F. Hassanat $(1)$ and C. Benchaar* (1)}

Agriculture and Agri-Food Canada, Sherbrooke Research and Development Centre, 2000 College Street, Sherbrooke, QC, Canada J1M 0C8

\section{ABSTRACT}

The objective of this study was to investigate the effects of forage source (red clover silage: RCS vs. corn silage: CS) and diet supplementation with linseed oil (LO) on $\mathrm{CH}_{4}$ emissions of manure from dairy cows. For this purpose, 12 lactating cows were used in a $2 \times 2$ factorial arrangement of treatments. Cows were fed (ad libitum) RCS- or CS-based diets (forage:concentrate ratio 60:40; dry matter basis) without or with LO addition (4\% dry matter). Feces and urine were collected from each cow and mixed with residual sludge obtained from a manure storage structure. Manure was incubated for 17 wk at $20^{\circ} \mathrm{C}$ under anaerobic conditions $\left(\mathrm{O}_{2}\right.$-free $\mathrm{N}_{2}$ ) in 500-mL glass bottles. Methane emissions and changes in chemical composition of the manure were monitored during the entire incubation period. The total amount of feces and urine excreted by cows was not affected by dietary treatments and averaged $6.6 \mathrm{~kg} / \mathrm{d}$ of volatile solids (VS). Compared with manure from cows fed RCS-based diets, maximum $\mathrm{CH}_{4}$ production potential of manure from cows fed CS-based diets was $54 \%$ higher (182 vs. $118 \mathrm{~L} / \mathrm{kg}$ of VS) throughout the incubation period. Maximum $\mathrm{CH}_{4}$ production potential from manure also increased (by 17\%) when cows were fed LO-supplemented diets compared with those fed nonsupplemented diets. Similar to maximum $\mathrm{CH}_{4}$ production potential, VS degraded during incubation (i.e., VS loss) was higher from manure from cows fed CS-based diets versus cows fed RCS-based diets (30.6 vs. $22.5 \%)$, and increased ( +3 percentage units, on average) with the addition of LO to the diets. Ammonia concentration in manure was higher when cows were fed CS-based diets compared with RCS-based diets, and declined with LO supplementation to CS and RCS diets. It is concluded that both dietary forage source and fat supplementation affect maximum $\mathrm{CH}_{4}$ production potential from manure and this should be taken into

Received November 19, 2018.

Accepted July 22, 2019.

*Corresponding author: chaouki.benchaar@canada.ca account when such dietary options are recommended to mitigate enteric $\mathrm{CH}_{4}$ emissions from dairy cows.

Key words: manure methane emissions, red clover silage, corn silage, linseed oil

\section{INTRODUCTION}

Current manure management contributes $24 \%$ of Canadian livestock greenhouse gas (GHG) emissions and $13 \%$ of GHG from Canadian agriculture $(8.5 \%$ of total national emissions) as reported by Environment Canada (2018). Extent of manure contribution to GHG emissions depends on many factors such as manure chemical composition, ambient temperature, and manure management practices, including storage duration, emptying frequency, and removal of residual sludge (Külling et al., 2002; Massé et al., 2008; Chadwick et al., 2011). Therefore, identifying factors that affect emissions from stored manure is essential for controlling contribution to GHG emissions. A survey (Agriculture and AgriFood Canada, 2016) showed that $31 \%$ of Canadian dairy farms practice solely liquid manure storage (in earth lagoons or tanks), $46 \%$ of dairy farms practice both liquid and solid manure storage, whereas $23 \%$ of dairy farms practice solely solid manure storage. Large proportion of stored liquid manure will be under strict anaerobic conditions, which promotes methanogenesis (Petersen, 2018).

Considerable efforts have been devoted to mitigate enteric $\mathrm{CH}_{4}$ emissions from dairy cows and several dietary and nutritional strategies have been proposed for this purpose (Beauchemin et al., 2009; Hassanat et al., 2013; Benchaar et al., 2015). However, these strategies often fall short in considering GHG emissions downstream (i.e., manure storage and management). Depending on manure management practices applied at the dairy operation, a given dietary strategy (e.g., fat supplementation) that reduces enteric $\mathrm{CH}_{4}$ emission (Brask et al., 2013) may increase $\mathrm{CH}_{4}$ emissions from stored manure (Møller et al., 2014). Additionally, the chemical composition of the diet may affect the that of the manure, which would eventually influence the magnitude of $\mathrm{CH}_{4}$ emissions during manure storage (Hales 
et al., 2012; Møller et al., 2014). Only few studies have investigated the effect of enteric $\mathrm{CH}_{4}$ mitigation strategies on $\mathrm{CH}_{4}$ emissions from stored manure (Brask et al., 2013; Møller et al., 2014).

In a previous study (Benchaar et al., 2015), we observed a decrease in daily enteric $\mathrm{CH}_{4}$ emissions $(\mathrm{g} / \mathrm{d}$ ) when linseed oil was added to diets of dairy cows based on either red clover silage (i.e., high-fiber and low-starch contents) or corn silage (i.e., low-fiber and high-starch contents) by 9 and $26 \%$, respectively. These dietary changes also influenced nutrient digestibility (i.e., fiber degradation) and consequently, manure chemical composition, which may affect $\mathrm{CH}_{4}$ emissions from stored manure. Thus, the objective of this study was to investigate the effect of forage source [red clover silage (RCS) vs. corn silage (CS)] and linseed oil (LO) supplementation on $\mathrm{CH}_{4}$ emissions of manure from dairy cows.

\section{MATERIALS AND METHODS}

This study was conducted at the Sherbrooke Research and Development Centre (Sherbrooke, Quebec, Canada). Animal procedures were conducted under the approval of the local Institutional Animal Care Committee and were in accordance with the guidelines of the Canadian Council on Animal Care (CCAC, 2009).

\section{Cows, Experimental Design, and Diets}

Twelve multiparous lactating Holstein cows were used in $2 \times 2$ factorial arrangement of treatments. The cows averaged (mean $\pm \mathrm{SD}$ ) $239 \pm 20 \mathrm{DIM}$ at the start of the experiment with BW of $742 \pm 60 \mathrm{~kg}$ and milk yield of $30 \pm 6.0 \mathrm{~kg} / \mathrm{d}$. During the experiment, cows were housed in individual tiestalls and had free access to water. Cows were fed (ad libitum; $5 \%$ orts on an as-fed basis) a TMR (60:40, forage:concentrate ratio) based (DM basis) on RCS $(57 \%)$ or CS $(57 \%)$ not supplemented or supplemented with $4 \%$ LO. The appropriate amount of LO (purity 98.2\%; Pokonobe Inc., Hudson, QC, Canada) was weighed daily and mixed thoroughly with the TMR. Composition (ingredients and chemical) of the experimental diets was provided in Benchaar et al. (2015). Briefly, the concentrate mixture consisted of corn grain (ground), soybean meal, rumen-bypass protein (AminoPlus, Hasting, NE), soybean hulls, rumen inert fat (Energy Booster 100, Milk Specialties Global Animal Nutrition, Carpentersville, IL), urea, and vitamin and mineral supplements. The chemical composition (\% DM basis) of the RCS-based diet without LO, RCS-based diet with LO, CS-based diet without LO, and CS-based diet with LO was as follows: CP: $16.5,16.3,16.6$, and $16.4 \%$, respectively; NDF: $36.2,35.6,29.6$, and $28.2 \%$, respectively; starch: $12.1,10.1,24.3$, and $22.0 \%$, respectively; ether extract (EE): $3.73,6.47,2.27$, and $5.84 \%$, respectively.

\section{Feces and Urine Collection}

Total collection of feces and urine was performed over 2 consecutive days by fitting cows with harnesses and tubes allowing the collection of feces and urine separately. Total urine was collected into reinforced plastic containers, whereas feces were collected from reinforced plastic mats placed behind the cow. Feces and urine were weighed daily, sampled (4\% of the amount excreted), mixed based on the daily excreted feces:urine ratio (on a fresh weight basis) and then pooled over the 2 collection days for each cow. Ratio of feces:urine averaged 2.0:1 and varied between cows from 1.5:1 to 2.5:1. Sub-samples were taken and stored at $-20^{\circ} \mathrm{C}$. They were subsequently freeze-dried and ground to pass a 1-mm screen using a Wiley mill (standard model 4; Thomas Scientific, Swedesboro, NJ) for later determination of DM, volatile solids (VS), NDF, ADF, ADL, total $\mathrm{N}$, and EE.

\section{Anaerobic Incubation of Manure}

The mixture of feces and urine of each cow was mixed manually (1:1) with psychrophilic residual sludge (i.e., inoculum) obtained from a manure storage structure at the dairy operation of the Sherbrooke Research and Development Centre. In this study, the mixture of feces, urine, and residual sludge was identified as manure. In Canada, the residual sludge to feces-urine ratio in the storage structure (i.e., pit) changes over time. When the producer starts to fill the manure storage in early May, the ratio of residual sludge to feces-urine is very high (approximately 8:1). With the addition of fecesurine in the storage facility over the summer time, the ratio decreases. At the end of the summer, the ratio of residual sludge to feces-urine could be as low as 1:8 (Massé et al., 2016). This is why an average ratio of 1:1 was selected for this experiment.

The $\mathrm{pH}$ of the manure was measured immediately and a representative sample $(50 \mathrm{~g})$ was diluted (1:1) with water, sub-sampled $(15 \mathrm{~mL})$, and frozen at $-20^{\circ} \mathrm{C}$ immediately for later determination of VFA concentrations. The manure was transferred under anaerobic conditions $\left(\mathrm{O}_{2}\right.$-free $\left.\mathrm{N}_{2}\right)$ into $500 \mathrm{~mL}$-glass bottles (6 replicates/cow; $250 \mathrm{~g}$ in each bottle), sealed with butyl rubber stoppers and aluminum seal (Wheaton, Millville, $\mathrm{NJ}$ ), and incubated at $20^{\circ} \mathrm{C}$ for $17 \mathrm{wk}$ in a controlled environment chamber. Of the 6 replicates, 3 replicates 
were used for gas production measurements, whereas 3 other replicates were used for determining fermentation characteristics of manure $(\mathrm{pH}$ and VFA concentrations). Blank bottles $(\mathrm{n}=3)$ containing residual sludge $(250 \mathrm{~g})$ were treated similarly for measurement of gas production. Thus, in total, 75 bottles were used in this study.

Concentration of DM in residual sludge was $6.3 \%$, and was composed (on DM basis) of $80.8 \%$ VS, $40.9 \%$ $\mathrm{NDF}$, and $4.0 \%$ total $\mathrm{N}$, whereas the $\mathrm{pH}$ was 7.51 . Methane emissions from the residual sludge after 17 wk of incubation were negligible and averaged $5.4 \mathrm{~L} /$ $\mathrm{kg}$ of VS.

\section{Gas Production Measurement}

Gas pressure in the bottle headspace was measured daily using a digital pressure gauge (Ashcroft 2089, Ashcroft Inc., Stratford, CT) and the volume of gas produced was calculated according to the following equation:

$$
\mathrm{P}_{1} \mathrm{~V}_{1}=\mathrm{P}_{2} \mathrm{~V}_{2} \text {, }
$$

where $\mathrm{P}_{1}=$ the atmospheric pressure, $\mathrm{V}_{1}=$ the volume of gas produced at atmospheric pressure, $\mathrm{P}_{2}=$ the pressure of gas measured at specific incubation day, and $\mathrm{V}_{2}$ $=$ the volume of headspace of the bottle.

Headspace gas was sampled using a syringe connected to the pressure gauge by a sampling valve. The collected gas sample was then forced into 6-mL screw-capped vacuum vials (Labco Ltd., Lampeter, UK) covered with a rubber septum (National Scientific, Rockwood, TN) for measurement of $\mathrm{CH}_{4}$ concentration. Gas pressure in the bottle head space was then reduced to room pressure by leaving the sampling syringe opened for $2 \mathrm{~min}$.

After 17 wk of anaerobic incubation, bottles $(\mathrm{n}=3)$ used for gas production measurements were weighed, their contents pooled, and sub-samples were frozen at $-20^{\circ} \mathrm{C}$ for later determination of DM, VS, and NDF concentrations. Losses of VS and NDF after $17 \mathrm{wk}$ of anaerobic incubation were calculated as the difference between VS and NDF contents at the beginning and at the end of the incubation period.

\section{Fermentation Characteristics of Manure}

Manure from each bottle was sampled under anaerobic conditions weekly up to wk 10 and then on wk 12, 14, and 17 of incubation. Bottle contents were homogenized by swirling, sampled (3.5 g/bottle) using a peristaltic pump (Accu-Jet, BRAND, Wertheim,
Germany) and plastic tubing, and then pooled across replicates. The small sample size $(1.4 \%$ of the original volume) ensured a minimum effect on the fermentation process of removing VS from the bottle. The $\mathrm{pH}$ was measured immediately and a sub-sample $(5 \mathrm{~mL})$ was stored at $-20^{\circ} \mathrm{C}$ for later determination of VFA concentrations. On wk 17 of incubation, a subsample (5 $\mathrm{mL}$ ) of manure was acidified to $\mathrm{pH} 2$ with $50 \%$ sulfuric acid and frozen at $-20^{\circ} \mathrm{C}$ for later determination of $\mathrm{NH}_{3}$ concentrations.

\section{Chemical Analyses}

Analytical DM content was determined by drying samples in a vacuum oven at $100^{\circ} \mathrm{C}$ overnight (AOAC International, 2005; method 934.01). Ash content was determined by incineration at $550^{\circ} \mathrm{C}$ overnight in a muffle furnace (AOAC International, 2005; method 942.05), and the VS content was calculated as the difference between 100 and the percentage of ash. Total $\mathrm{N}$ was determined using the macro-Kjeldahl procedure (AOAC International, 2005; method 954.01). The concentration of NDF was determined as described by Van Soest et al. (1991). The ADF and ADL contents were determined according to AOAC International (2005; method 973.18). The NDF, ADF, and ADL procedures were adapted for use in an Ankom ${ }^{200}$ Fiber Analyzer (Ankom Technology Corp., Fairport, NY). Ether extract (AOAC International, 2005; method 920.39) was determined using the Soxtec 2047 Soxcap in combination with Soxtec extraction systems (Foss, Eden Prairie, $\mathrm{MN})$.

Analysis of VFA was performed using a gas chromatograph equipped with a flame ionization detector and auto-injector (Perkin-Elmer, Norwalk, CT) fitted with DB-FFAP column $(30 \mathrm{~m} \times 0.53 \mathrm{~mm} \times 1 \mu \mathrm{m}$; J\&W Scientific, Folsom, CA) with $\mathrm{He}$ as the carrier gas. The gas flow in the column was fixed at $5 \mathrm{~mL} / \mathrm{min}$; oven temperature was fixed at $135^{\circ} \mathrm{C}$; and total run time was $8 \mathrm{~min}$. Injector and detector temperatures were 200 and $250^{\circ} \mathrm{C}$, respectively. Gas flows at the detector were 45 and $450 \mathrm{~mL} / \mathrm{min}$ for $\mathrm{H}_{2}$ and air, respectively. Ammonia was determined as in Weatherburn (1967). Analysis of $\mathrm{CH}_{4}$ was performed using GC (490 Micro GC, Agilent Technologies, Amstelveen, North Holland, the Netherlands) equipped with a $10 \mathrm{~m}$ PPQ column (Agilent Technologies) and a thermal conductivity detector. Column temperature was fixed at $70^{\circ} \mathrm{C}$, whereas injector and detector temperature was fixed at 110 and $70^{\circ} \mathrm{C}$, respectively. The column was operated at a carrier gas (He) pressure of $138 \mathrm{kPa}$, with elution time of 1 min. Calibration was done using standard gas mixtures containing different proportions of $\mathrm{CH}_{4}$. 


\section{Statistical Analyses}

Data were analyzed using the MIXED procedure of SAS (SAS Institute Inc., Cary, NC) in a $2 \times 2$ factorial arrangement of treatments. The statistical model included LO supplementation (i.e., with vs. without LO), silage source (i.e., CS vs. RCS), and LO supplementation $\times$ silage source interaction as fixed effects. Cows were the experimental units. Data of $\mathrm{CH}_{4}$ production were summarized by week. Methane production, $\mathrm{pH}$, and VFA concentrations were analyzed as repeated measures using the same model with the addition of week and week $\times$ treatment interactions as fixed effects. The appropriate covariance structure used for repeated-measures analyses was chosen to achieve lowest Akaike, corrected Akaike, and Bayesian information criteria values. Cow within treatment was the subject of the repeated measures. Significant effects of treatments were declared at $P \leq 0.05$ and tendencies at 0.05 $<P \leq 0.10$.

\section{RESULTS AND DISCUSSION}

\section{Chemical Composition of the Mixture of Feces and Urine}

Chemical composition of feces and urine mixture is presented in Table 1. The amount of VS averaged $6.6 \mathrm{~kg} / \mathrm{cow}$ per day and was not influenced by dietary treatments. Quantity of VS is in the upper limit of the value of $5.4 \pm 1.1 \mathrm{~kg} /$ cow per day suggested by the IPCC (2006).

The mixture of feces and urine from cows fed CSbased diets contained a higher $(P \leq 0.04)$ concentration of VS (84.3 vs. $83.0 \%$ ), NDF (47.3 vs. $36.8 \%$ ), and $\operatorname{ADF}(27.8$ vs. $25.0 \%$ ) than that from cows fed RCS-based diets (Table 1). The fiber fraction of the mixture from cows fed CS-based diets contained almost $50 \%$ less lignin (12.6 vs. $23.2 \% ; P<0.01$ ) than the fiber fraction of the mixture from cows fed RCS-based diets. Benchaar et al. (2015) reported lower fiber digestibility in cows fed CS-based diets versus cows fed RCS-based diets (50.6 vs. $66.2 \%$ ). Because lignin is not digestible, the decline in fiber digestibility in cows fed CS-based diets compared with cows fed RCS-based diets increased cellulose and hemicellulose concentrations and, consequently, decreased lignin concentration in feces. Similarly, Møller et al. (2014) observed higher VS and fiber contents in feces of cows fed CS-based (i.e., high-starch content) diets compared with feces of cows fed early harvest grass-clover silage-based diets (i.e., low-starch content). Massé et al. (2016) also reported an increase in NDF excretion by cows when corn silage completely replaced alfalfa silage in the diet. In our previous study (Benchaar et al., 2015), high-starch content of CS-based diets compared with RCS-based diets (23.2 vs. $11.1 \%)$ impaired NDF digestion. Similar observations (Brask et al., 2013; Hassanat et al., 2013; Arndt et al., 2015) were reported in dairy cows fed high-starch diets (i.e., CS-based diets) versus lowstarch diets (legume- or grass silage-based diets).

Nitrogen concentration in the mixture of feces and urine from cows fed CS-based diets was higher $(P=$ 0.01) than in that from cows fed RCS-based diets, which is mainly related to differences in dietary $\mathrm{CP}$ source. In the RCS-based diets the main CP sources were the RCS and rumen-bypass protein supplement. In the CS-based diets, the main CP source was soybean meal. Compared with feeding CS-based diets, feeding RCS-based diets restricted degradation of dietary protein in the rumen due to the presence of polyphenols in RCS that inhibit protein degradation in the rumen (Broderick et al., 2007; Powell et al., 2009) and to the lower ruminal degradability of the rumen bypass pro-

Table 1. Volatile solids and composition of the mixture of urine and feces from lactating cows fed diets based on red clover silage (RCS) or corn silage (CS) without (-) or with (+) linseed oil (LO) supplementation

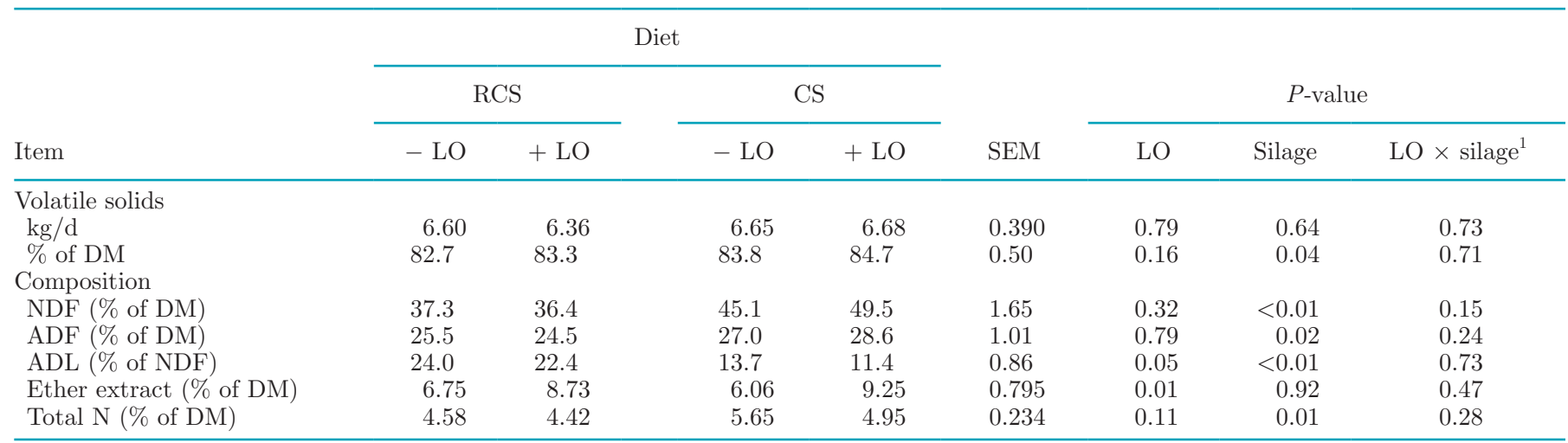

${ }^{1}$ Interaction between LO supplementation (with vs. without) and silage source (CS vs. RCS). 


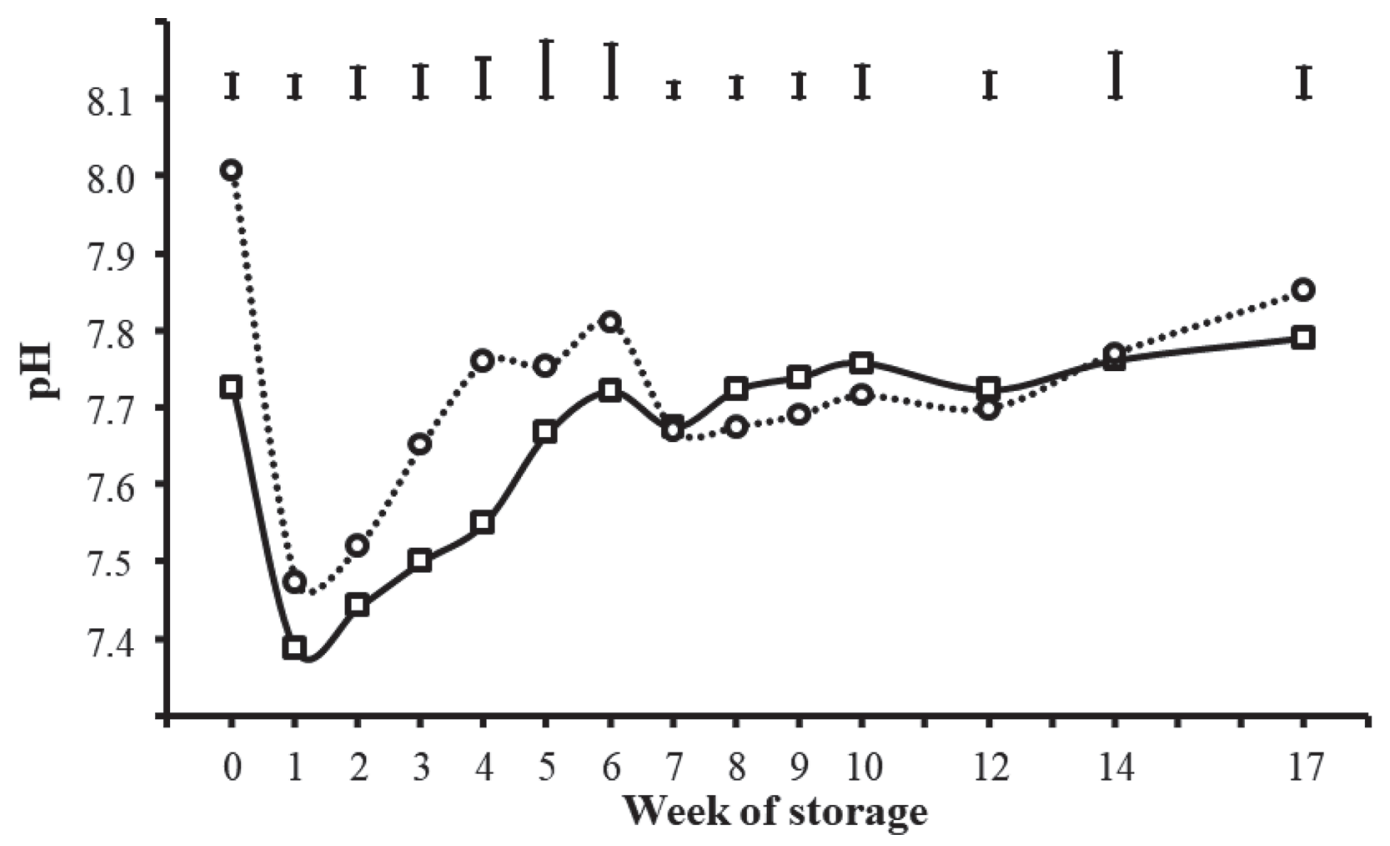

Figure 1. Changes in $\mathrm{pH}$ of incubated manure from cows fed diets based on red clover silage $(\square)$ or corn silage $(\bigcirc)$ during the 17 wk of anaerobic incubation (no significant effect of linseed oil on $\mathrm{pH}$ ). Error bars are SEM.

tein supplement compared with soybean meal. Extensive ruminal degradation of dietary $\mathrm{CP}$ when cows were fed the CS-based diets versus RCS-based diets have led to an increase of $\mathrm{N}$ excretion in urine as reported in Benchaar et al. (2015).

Ether extract (i.e., fat) content of the mixture of feces and urine increased $(P=0.01)$ with LO supplementation to RCS- and CS-based diets (+2.6 percentage units, on average). Supplementing RCS- and CS-based diets with LO doubled EE concentration in the diet, which would explain the increased EE concentration in feces and urine mixture from cows fed LO-supplemented diets compared with the mixture from cows fed nonsupplemented diets. Likewise, an increase of fecal EE concentration was observed in dairy cows fed lipidsupplemented diets (Massé et al., 2014; Møller et al., 2014). Supplementation of LO to RCS- and CS-based diets reduced $(-12 \%, P=0.05)$ ADL (i.e., lignin) concentration in the NDF fraction of the mixture of feces and urine.

\section{Fermentation Characteristics of Incubated Manure}

Interactions between LO supplementation, silage source, and incubation week; or between LO supplementation and incubation week were not significant for fermentation characteristics of manure. Throughout the incubation period, adding $\mathrm{LO}$ had no effect on $\mathrm{pH}$ (7.69 vs. 7.68 ), total VFA (24.0 vs. $22.1 \mathrm{mM}$ ), and acetate (17.8 vs. $16.0 \mathrm{mM}$ ) in manure from cows fed nonsupple- mented and LO-supplemented diets, respectively. An interaction between silage source and sampling week was observed for $\mathrm{pH}$ and concentrations total VFA and acetate. The $\mathrm{pH}$ declined in the first week of incubation and then gradually increased thereafter (Figure 1). The $\mathrm{pH}$ of manure from cows fed CS-based diets was higher than manure from cows fed RCS-based diets on wk 0, 1,3 , and 4 of incubation, but not different on the other weeks of incubation (i.e., silage $\times$ week interaction, $P$ $=0.02$ ).

Concentrations of total VFA (Figure 2) and acetate (Figure 3) increased in the first and second week of incubation of manure from cows fed CS-based diets and RCS-based diets, respectively, and then declined, which explains the observed changes in $\mathrm{pH}$. Similar changes in $\mathrm{pH}$ and VFA concentrations during manure incubation have been previously reported (Hales et al., 2012; Barret et al., 2013). According to Ahring (2003), Demirel and Scherer (2008), and Barret et al. (2012), the increase in total VFA and acetate concentrations is due to activities of acidogenic and acetogenic bacteria to degrade manure VS to VFA. These activities surpassed the capacity of methanogenic Archaea to degrade acetate, leading to an accumulation of VFA and a decline in $\mathrm{pH}$ of manure. Afterward, the activities of acetotrophic methanogens to degrade acetate and hydrogenotrophic methanogens to consume $\mathrm{H}_{2}$ for $\mathrm{CH}_{4}$ production surpassed the activities of acidogenic and acetogenic bacteria, leading to a depletion of VFA and increase in $\mathrm{pH}$ of manure. Concentrations of total VFA 


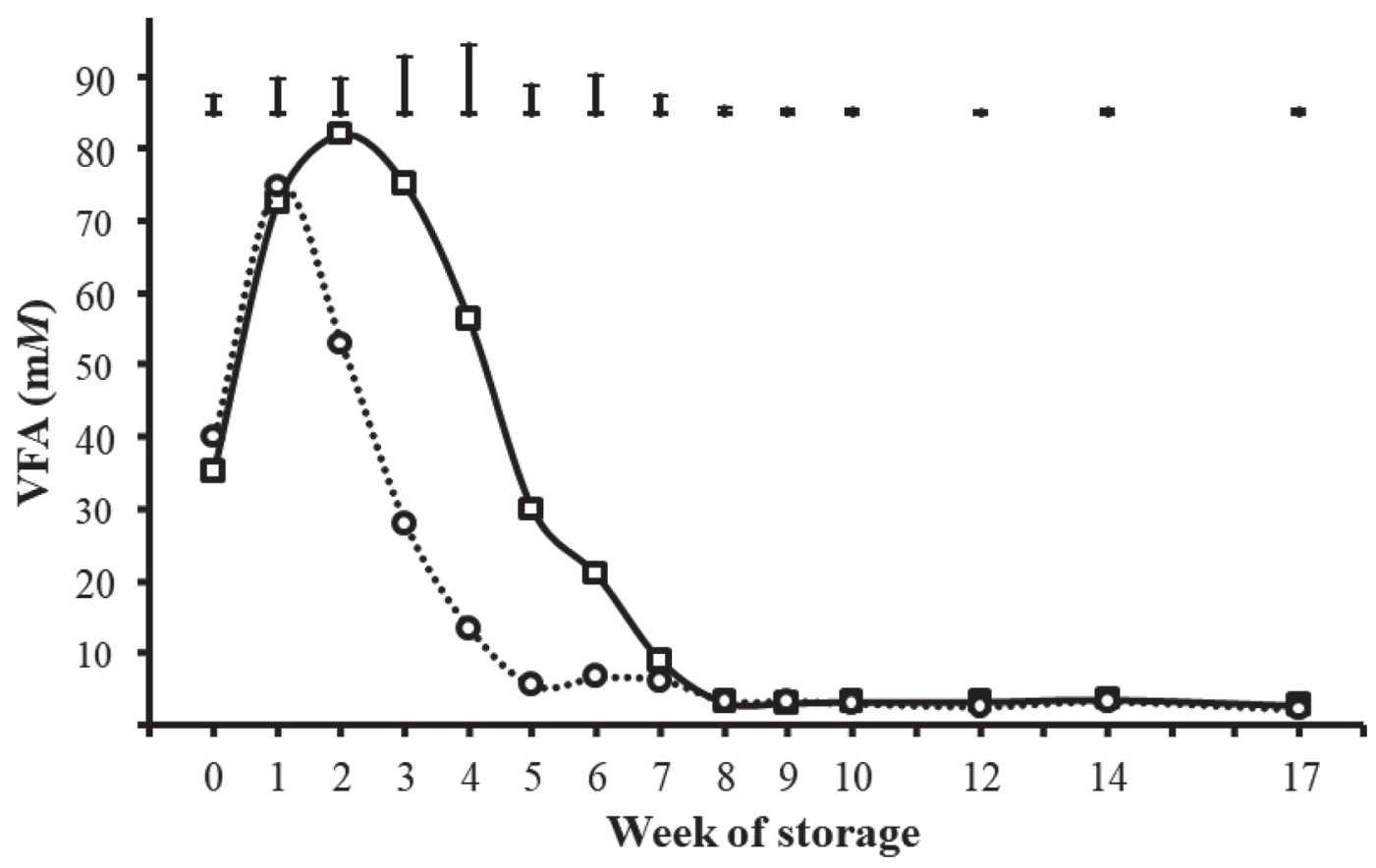

Figure 2. Total VFA concentration in incubated manure from cows fed diets based on red clover silage $(\square)$ or corn silage $(\bigcirc)$ during the 17 wk of anaerobic incubation (no significant effect of linseed oil on total VFA concentration). Error bars are SEM.

and acetate in manure from cows fed CS-based diets were lower than in manure from cows fed RCS-based diets from wk 2 to 5 of incubation, but no differences were observed for the remaining weeks (i.e., silage $x$ week interaction, $P<0.01$ ).

\section{Methane Production from Manure}

Kinetics of $\mathrm{CH}_{4}$ production during the 17 wk of anaerobic incubation of manure are shown in Figure 4. A significant $(P<0.01)$ interaction between LO supplementation, silage source, and incubation week was observed for $\mathrm{CH}_{4}$ production. Methane production started at the onset of incubation, so there was no lag time for any treatment. At any week of incubation, manure from cows fed CS-based diets produced more $(P<$ 0.01) $\mathrm{CH}_{4}$ than manure from cows fed RCS-based diets. From the initiation of the incubation up to wk $6, \mathrm{CH}_{4}$ production was similar for manure from cows fed the nonsupplemented CS-based diet and manure from cows fed the LO-supplemented CS-based diet. However, from wk 7 to $17, \mathrm{CH}_{4}$ production was higher $(P \leq 0.05)$ for the manure from cows fed the LO-supplemented CSbased diet compared with the manure from cows fed the nonsupplemented CS-based diet. The same kinetics of $\mathrm{CH}_{4}$ production was also observed with the addition of $\mathrm{LO}$ to the RCS-based diet: $\mathrm{CH}_{4}$ production from manure was not affected by LO supplementation to the RCS-based diet from the beginning of incubation up to wk 12 of incubation. Starting from wk 13 to the end of the incubation period, manure from cows fed the LO-supplemented RCS-based diet tended $(0.05<$ $P \leq 0.10)$ to produce more $\mathrm{CH}_{4}$ compared with the manure from cows fed the nonsupplemented RCS-based diet. Peaks of $\mathrm{CH}_{4}$ production from manure of cows fed nonsupplemented and LO-supplemented CS-based diets (22.5 and $24.0 \mathrm{~L}$ of $\mathrm{CH}_{4} / \mathrm{kg}$ of $\mathrm{VS}$, respectively) were observed on wk 3 of incubation (data not shown). However, peaks of $\mathrm{CH}_{4}$ production from manure of cows fed nonsupplemented and LO-supplemented RCSbased diets (13.6 and 12.7 $\mathrm{L}$ of $\mathrm{CH}_{4} / \mathrm{kg}$ of VS, respectively) were observed on wk 5 of incubation (data not shown). Maximum $\mathrm{CH}_{4}$ production potential was 109, 126, 166, and $197 \mathrm{~L} / \mathrm{kg}$ of VS for the nonsupplemented RCS-based diet, the LO-supplemented RCS-based diet, the nonsupplemented CS-based diet, and the LO-supplemented CS-based diet, respectively (Table 2).

After $17 \mathrm{wk}$ of incubation, manure from cows fed CS-based diets produced $54 \%$ more $(P<0.01) \mathrm{CH}_{4}$ per kilogram of VS than manure from cows fed RCSbased diets (182 vs. $118 \mathrm{~L} / \mathrm{kg}$ of VS; Table 2). This difference in maximum $\mathrm{CH}_{4}$ production potential is a result of the higher NDF content and the lower lignin concentration in the fiber fraction of the manure from cows fed CS-based diets versus the manure from cows fed RCS-based diets. In agreement, Amon et al. (2007) observed lower manure lignin concentration associated with increased $\mathrm{CH}_{4}$ emissions of manure from cows fed 


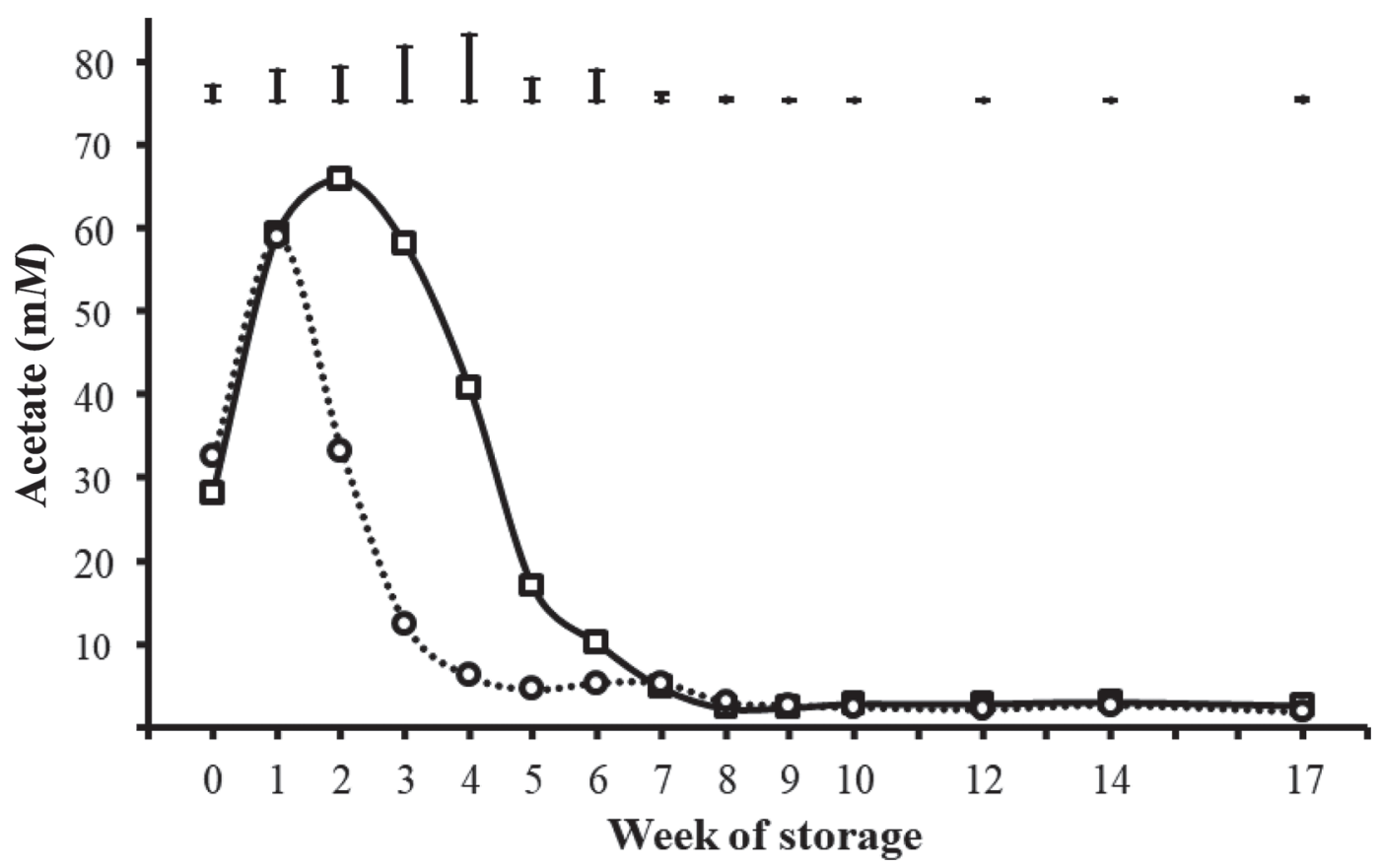

Figure 3. Acetate concentration in incubated manure from cows fed diets based on red clover silage $(\square)$ or corn silage $(\bigcirc)$ during the 17 wk of anaerobic incubation (no effect of linseed oil on acetate concentration). Error bars are SEM.

corn silage compared with cows fed grass silage. Doreau et al. (2014) observed a decline in NDF digestibility (increase in degradable NDF concentration in manure) and an increase in predicted (IPCC-Tier 2; IPCC, 2006) $\mathrm{CH}_{4}$ emissions from manure when corn silage replaced grass silage in dairy cow diets. Also, Massé et al. (2016) reported higher $(+86 \%) \mathrm{CH}_{4}$ emissions of manure from cows fed corn silage-based diet compared with emission of manure from cows fed alfalfa silage-based diet (158.5 vs. $85.4 \mathrm{~L} / \mathrm{kg}$ of VS). Lignin has been identified as a major factor affecting $\mathrm{CH}_{4}$ production from anaerobic biodegradation of organic waste (Stinson and Ham, 1995; Molinuevo-Salces et al., 2013; Massé and Saady, 2015).

Several studies have reported a direct relationship between the concentration of VFA and $\mathrm{CH}_{4}$ production of stored manure (Pind et al., 2003; Dennehy et al., 2016; Lu et al., 2017). In contrast, in the current study, the higher $\mathrm{CH}_{4}$ emissions of manure from cows fed CSbased diets compared with manure of cows RCS-based diets was associated with lower total VFA concentrations during wk 2 to 5 of incubation. We attempt to speculate that methanogenic bacteria were established more rapidly in manure from cows fed CS-based diets, leading to higher VFA consumption and, consequently, lower VFA concentration (wk 2-5 of incubation) compared with manure from cows fed RCS-based diets. Peaks of $\mathrm{CH}_{4}$ production of manure from cows fed CS-based diets (23 L/kg of VS) were observed on wk
3 of incubation, whereas peaks of $\mathrm{CH}_{4}$ production of manure from cows fed RCS-based diets ( $13 \mathrm{~L} / \mathrm{kg}$ of VS) were observed on wk 5 of incubation. This may explain the lower VFA concentration (wk 2-5) in manure from cows fed CS-based diets compared with manure from cows fed RCS-based diets, whereas $\mathrm{CH}_{4}$ emissions of manure from cows fed the CS-based diet were higher.

Maximum $\mathrm{CH}_{4}$ production potential (i.e., after $17 \mathrm{wk}$ of anaerobic incubation) from manure was $17 \%$ higher when cows were fed LO-supplemented diets versus nonsupplemented diets (Table 2). The additional fat in manure from cows fed LO-supplemented diets compared with cows fed nonsupplemented diets was more likely degraded during incubation and contributed to $\mathrm{CH}_{4}$ production. Møller et al. (2014) observed that dietary fat supplementation increased fecal fat concentration and was associated with an increase in $\mathrm{CH}_{4}$ emissions from manure. Furthermore, the low lignin concentration and the consequent increased degradable fiber content in manure when cows were fed LO-supplemented diets compared with nonsupplemented diets may have contributed to higher $\mathrm{CH}_{4}$ emissions during incubation.

A single default value $(240 \pm 36 \mathrm{~L} / \mathrm{kg}$ of VS $)$ has been suggested by IPCC (Tier 2; IPCC, 2006) as the maximal $\mathrm{CH}_{4}$ producing capacity $\left(\mathrm{B}_{0}\right)$ for manure from dairy cows in North America. In the current study, maximum $\mathrm{CH}_{4}$ production potential of manure from cows fed the experimental diets (109 to $197 \mathrm{~L} / \mathrm{kg}$ of VS; Table 2) is lower than the default value reported 


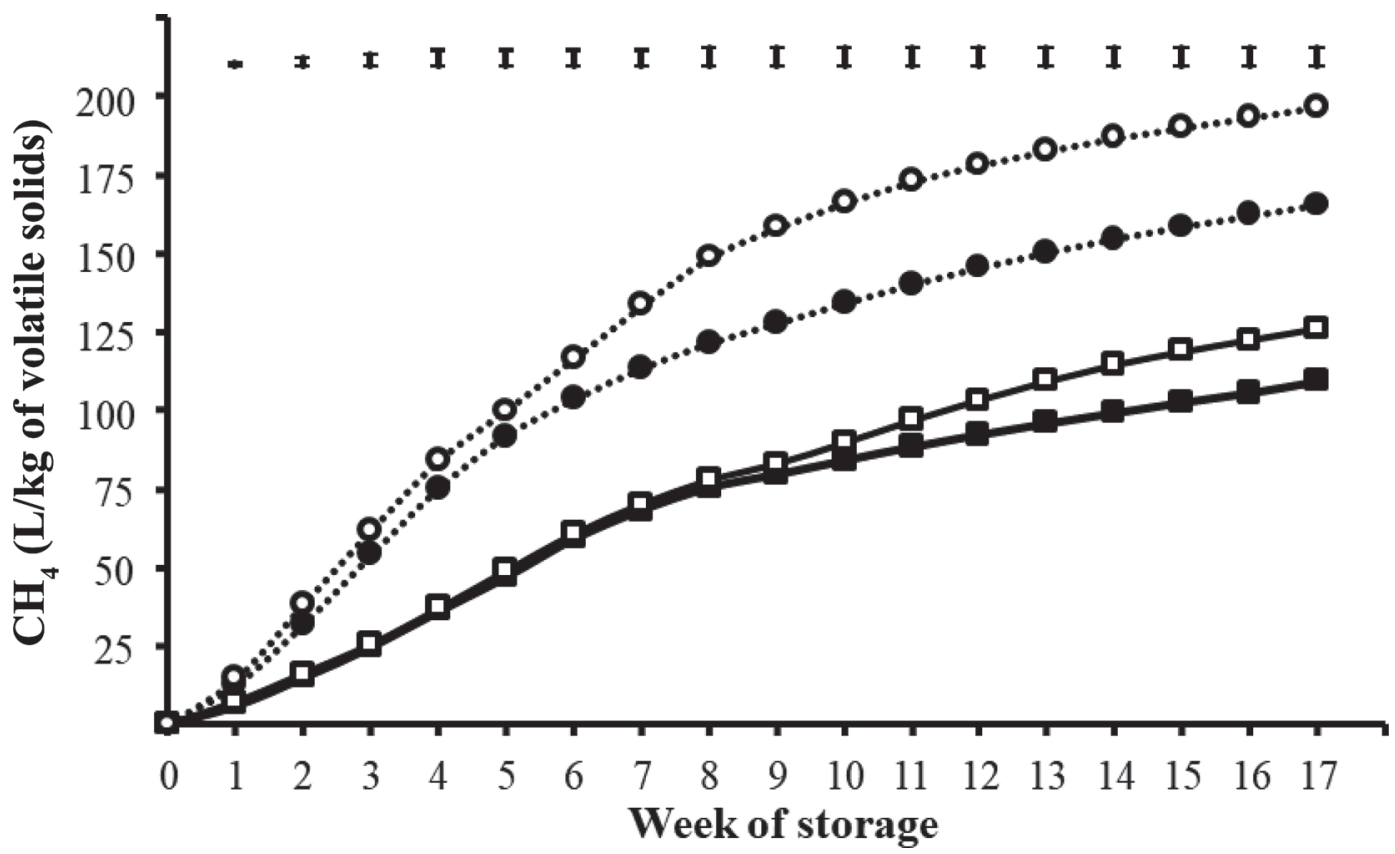

Figure 4. Methane production of incubated manure from cows fed diets based on red clover silage without $(\boldsymbol{\square})$ or with $(\square)$ linseed oil, or corn silage without $(\bullet)$ or with $(\bigcirc)$ linseed oil. Error bars are SEM.

by the IPCC (Tier 2; IPCC, 2006). These discrepancies transpire because the default value suggested by the IPCC (Tier 2; IPCC, 2006) does not take into account the influence of the diet and its effect on chemical composition or degradability of manure VS, or both. Thus, improving accuracy of estimation of $\mathrm{CH}_{4}$ emissions from stored manure requires the development of maximal $\mathrm{CH}_{4}$ producing capacity factors that take into consideration the effect of the diet on VS manure composition.

In the current study, daily manure $\mathrm{CH}_{4}$ emissions were calculated according to the equation 10.23 of IPCC
(Tier 2; IPCC, 2006) using quantity of VS excreted (Table 1), values of maximum $\mathrm{CH}_{4}$ production potential of manure from cows fed the dietary treatments (Table 2), and the $\mathrm{CH}_{4}$ conversion factor suggested by Environment Canada (2015). Based on these calculations (Table 2), $\mathrm{CH}_{4}$ emission of manure was $97 \mathrm{~g} / \mathrm{d}$ for the nonsupplemented RCS based-diet, $108 \mathrm{~g} / \mathrm{d}$ for the LO-supplemented RCS-based diet, $148 \mathrm{~g} / \mathrm{d}$ for the nonsupplemented CS-based diet, and $177 \mathrm{~g} / \mathrm{d}$ for the LO-supplemented CS-based diet (Table 2). In a previous study (Benchaar et al., 2015), enteric $\mathrm{CH}_{4}$ emission was $500 \mathrm{~g} / \mathrm{d}$ for the nonsupplemented RCS-based diet,

Table 2. Methane productions, volatile solids (VS), NDF losses, and $\mathrm{NH}_{3}$ concentration in incubated manure from lactating cows fed diets based on red clover silage (RCS) or corn silage (CS) without (-) or with (+) linseed oil (LO) supplementation

\begin{tabular}{|c|c|c|c|c|c|c|c|c|}
\hline Item & \multicolumn{4}{|c|}{ Diet } & SEM & \multicolumn{3}{|c|}{$P$-value } \\
\hline \multicolumn{9}{|l|}{$\mathrm{CH}_{4}$} \\
\hline Maximal production (L/kg of VS) & 109 & 126 & 166 & 197 & 5.5 & $<0.01$ & $<0.01$ & 0.23 \\
\hline $\operatorname{Emission}^{2}(\mathrm{~g} / \mathrm{d})$ & 97 & 108 & 148 & 177 & 11.3 & 0.11 & $<0.01$ & 0.42 \\
\hline \multicolumn{9}{|l|}{$\mathrm{NH}_{3}$} \\
\hline $\mathrm{m} M$ & 203 & 195 & 246 & 222 & 7.40 & 0.06 & $<0.01$ & 0.30 \\
\hline$\%$ of $\mathrm{N}$ & 71.1 & 68.4 & 76.0 & 74.2 & 2.74 & 0.43 & 0.09 & 0.88 \\
\hline
\end{tabular}

${ }^{1}$ Interaction between LO supplementation (with versus without) and silage source (CS vs. RCS).

${ }^{2}$ Calculated according to the equation 10.23 (IPCC-Tier 2; IPCC, 2006) using VS excretion (Table 1), $\mathrm{CH}_{4}$ maximal production (L/kg of VS) of manure from cows, and the $\mathrm{CH}_{4}$ conversion factor as suggested by Environment Canada (2015). 
$453 \mathrm{~g} / \mathrm{d}$ for the LO-supplemented RCS-based diet, 491 $\mathrm{g} / \mathrm{d}$ for the nonsupplemented CS-based diet, and 362 $\mathrm{g} / \mathrm{d}$ for the LO-supplemented CS-based diet. Total $\mathrm{CH}_{4}$ emission (sum of enteric and manure emissions) was 597 $\mathrm{g} / \mathrm{d}$ for the nonsupplemented RCS based-diet, $561 \mathrm{~g} / \mathrm{d}$ for the LO-supplemented RCS based-diet, $639 \mathrm{~g} / \mathrm{d}$ for the nonsupplemented CS-based diet, and $539 \mathrm{~g} / \mathrm{d}$ for the LO-supplemented CS-based diet (data not shown). When expressed as a percentage of total emission, manure emission was $16.2 \%$ for the nonsupplemented RCS based-diet, $19.2 \%$ for the LO-supplemented RCS baseddiet, $23.2 \%$ for the nonsupplemented CS-based diet, and $32.8 \%$ for the LO-supplemented CS-based diet.

Supplementing the RCS-based diet with LO reduced enteric $\mathrm{CH}_{4}$ emissions by $47 \mathrm{~g} / \mathrm{d}$ (Benchaar et al., 2015) but increased manure $\mathrm{CH}_{4}$ emissions by 11 $\mathrm{g} / \mathrm{d}$, resulting in a net decline in total $\mathrm{CH}_{4}$ emissions by $36 \mathrm{~g} / \mathrm{d}$. Supplementing the CS-based diet with LO reduced enteric $\mathrm{CH}_{4}$ emissions by $129 \mathrm{~g} / \mathrm{d}$ (Benchaar et al., 2015) but increased manure $\mathrm{CH}_{4}$ emissions by 29 $\mathrm{g} / \mathrm{d}$, resulting in a net decline in total $\mathrm{CH}_{4}$ emissions by $100 \mathrm{~g} / \mathrm{d}$. Therefore, LO supplementation to RCS- or CS-based diets reduced total $\mathrm{CH}_{4}$ emissions (by 6 and $16 \%$, respectively). Meanwhile, compared with feeding the nonsupplemented RCS-based diet, feeding cows the nonsupplemented CS-based diet reduced slightly enteric $\mathrm{CH}_{4}$ emissions $(-9 \mathrm{~g} / \mathrm{d})$, but increased manure $\mathrm{CH}_{4}$ emissions $(+51 \mathrm{~g} / \mathrm{d})$, resulting in a net increase in total $\mathrm{CH}_{4}$ emissions by $42 \mathrm{~g} / \mathrm{d}(+7 \%)$. Taken together, these results provide evidence that the gain achieved via dietary enteric $\mathrm{CH}_{4}$ mitigation may be offset by an increase of $\mathrm{CH}_{4}$ emissions from stored manure. Therefore, changes in $\mathrm{CH}_{4}$ emissions from manure storage should be evaluated before recommending any dietary mitigation strategy aiming to reduce enteric $\mathrm{CH}_{4}$ emission from dairy cows.

In our previous study (Benchaar et al., 2015), milk yield was $37.5,38.1,37.9$, and $32.7 \mathrm{~g} / \mathrm{kg}$ of ECM for cows fed nonsupplemented RCS-, supplemented RCS-, nonsupplemented CS-, and supplemented CS-based diets, respectively. When expressed on a milk yield basis, total $\mathrm{CH}_{4}$ emission was $15.9,14.7,16.9$, and $16.5 \mathrm{~g} /$ $\mathrm{kg}$ of ECM for nonsupplemented RCS-, supplemented RCS-, nonsupplemented CS-, and supplemented CSbased diets, respectively. These results reveal that total $\mathrm{CH}_{4}$ emissions reported on ECM yield basis were higher for cows fed CS versus cows fed RCS (16.7 vs. $15.3 \mathrm{~g} /$ $\mathrm{kg}$ of ECM). Supplemented RCS-based diet with LO decreased $(8 \%)$ total $\mathrm{CH}_{4}$ emission $(\mathrm{g} / \mathrm{kg}$ of $\mathrm{ECM})$, whereas only a small reduction $(2 \%)$ was observed when LO was added in the CS-based diet.

It is worthy to note that in the present study, maximum $\mathrm{CH}_{4}$ production potential from manure were measured under controlled environment (anaerobic conditions for 17 wk at $20^{\circ} \mathrm{C}$ ). Large proportion of liquid manure stored in dairy farms in temperate regions would be under conditions similar to those applied in the current study. Maximum $\mathrm{CH}_{4}$ production potential $\left(\mathrm{B}_{0}\right)$ is commonly determined through batch anaerobic incubation of manure (Molinuevo-Salces et al., 2013; Møller et al., 2014; VanderZaag et al., 2018). However, many other factors can influence $\mathrm{CH}_{4}$ emission from stored manure. Such factors may include environmental conditions (air, temperature, sun, humidity), storage facility, residual sludge proportion in the storage facility, and storage duration as reported in Massé et al. (2008) and Petersen (2018). As a consequence, $\mathrm{CH}_{4}$ emissions (g/d) estimated based on $\mathrm{B}_{0}$ determination may not reflect emissions occurring under farming conditions.

Losses of VS and NDF of manure from cows fed CSbased diets (Table 2$)$ were higher $(P<0.01)$ than losses of manure from cows fed RCS-based diets (31 vs. $23 \%$ and 34 vs. $18 \%$ for VS and NDF, respectively). This is consistent with the higher maximum $\mathrm{CH}_{4}$ production potential of manure from cows fed CS-based diets compared with those fed RCS-based diets. Diet (RCSand CS-based) supplementation with LO increased $(+3$ percentage units, on average; $P=0.04)$ VS losses, which is also consistent with the increase in maximum $\mathrm{CH}_{4}$ production potential of manure from cows fed LOsupplemented diets compared with nonsupplemented diets. Aguerre et al. (2012) reported that loss of VS and NDF during manure storage $\left(136 \mathrm{~d}\right.$ at $\left.18^{\circ} \mathrm{C}\right)$ averaged 31 and $23 \%$, respectively, which is close to the values observed in this study.

\section{Ammonia Concentration in Incubated Manure}

After 17 wk of incubation, $\mathrm{NH}_{3}$ (concentration and as a proportion of total $\mathrm{N}$ ) in manure (Table 2) were higher for cows fed CS-based diets compared with cows fed RCS-based diets $(P=0.01$ and $P=0.09$, respectively). This is due to the higher urinary $\mathrm{N}$ excretion $(\mathrm{g} / \mathrm{d})$ by cows fed CS-based diets versus cows fed RCS-based diets, as observed in Benchaar et al. (2015). Urinary N is mainly excreted in the form of urea, which is rapidly degraded to $\mathrm{NH}_{3}$ in manure (Petersen, 2018). Ammonia concentration tended to be lower $(P=0.06)$ in manure from cows fed LO-supplemented diets compared with cows fed nonsupplemented diets (Table 2). This can be related to a decrease in urinary $\mathrm{N}$ excretion when cows were fed LO-supplemented versus nonsupplemented diets (Benchaar et al., 2015). Potential $\mathrm{NH}_{3}$ and $\mathrm{N}_{2} \mathrm{O}$ emissions are expected to be higher of manure from cows fed CS-based diets versus RCS-based diets and of manure from cows fed nonsupplemented versus LOsupplemented diets after field application. Emissions of $\mathrm{NH}_{3}$ and $\mathrm{N}_{2} \mathrm{O}$ after field application of manure are posi- 
tively related to $\mathrm{NH}_{3}$ concentration in manure before application (Chadwick et al., 2011; Petersen, 2018).

\section{CONCLUSIONS}

This study demonstrates that the composition of the diet (i.e., forage source, fat supplementation) and its digestibility can have a major influence of $\mathrm{CH}_{4}$ emissions potential from manure of dairy cows. Maximum $\mathrm{CH}_{4}$ production potential ( $/ \mathrm{kg}$ of VS) from manure kept under anaerobic conditions for 17 wk increased by $54 \%$ when cows were fed CS-based diets (i.e., low-fiber and high-starch contents) versus RCS-based diets (i.e., high-fiber and low-starch contents). Supplementing diets with $4 \% \mathrm{LO}$ increased maximum $\mathrm{CH}_{4}$ production potential from manure by $17 \%$. Such increases in manure emissions counterbalanced the gain achieved through the reduction in enteric $\mathrm{CH}_{4}$ emissions. Methane emissions $(\mathrm{g} / \mathrm{d})$ determined under controlled environment are applicable to the specific conditions of the present study because under farming conditions, other factors may influence emissions from stored manure (e.g., climate conditions, storage facility, storage duration). Finally, manure emissions must be considered in the context of total animal (i.e., $\mathrm{CH}_{4}$ ) and the lactational performance of the cows. Accuracy of estimation of $\mathrm{CH}_{4}$ emissions from manure storage (e.g., IPCC) therefore can be improved by taking into account the effects of diets on manure composition.

\section{ACKNOWLEDGMENTS}

The authors thank L. Croteau and S. Provencher for technical assistance, S. Méthot for his help with statistical analyses, and the barn crew for care of the animals (all from the Sherbrooke Research and Development Centre, Agriculture and Agri-Food Canada, Sherbrooke, Quebec, Canada). The study was funded through Dairy Research Cluster grant from the Agriculture and Agri-Food Canada (Ottawa, ON), the Dairy Farmers of Canada (Ottawa, ON), and the Canadian Dairy Commission (Ottawa, ON).

\section{REFERENCES}

Agriculture and Agri-Food Canada. 2016. Manure Storage on Canadian Farms from the Farm Environmental Management Survey (FEMS) 2011. Minister of Agriculture and Agri-Food.

Aguerre, M. J., M. A. Wattiaux, and J. M. Powell. 2012. Emissions of ammonia, nitrous oxide, methane, and carbon dioxide during storage of dairy cow manure as affected by dietary forage-to-concentrate ratio and crust formation. J. Dairy Sci. 95:7409-7416. https: //doi.org/10.3168/jds.2012-5340.

Ahring, B. K. 2003. Perspectives for anaerobic digestion. Adv. Biochem. Eng. Biotechnol. 81:1-30.
Amon, T., B. Amon, V. Kryvoruchko, W. Zollitsch, K. Mayer, and L. Gruber. 2007. Biogas production from maize and dairy cattle manure - Influence of biomass composition on the methane yield. Agric. Ecosyst. Environ. 118:173-182. https://doi.org/10.1016/j agee.2006.05.007.

AOAC International. 2005. Official Methods of Analysis. 18th ed. AOAC International, Arlington, VA.

Arndt, C., J. M. Powell, M. J. Aguerre, and M. A. Wattiaux. 2015. Performance, digestion, nitrogen balance, and emission of manure ammonia, enteric methane, and carbon dioxide in lactating cows fed diets with varying alfalfa silage-to-corn silage ratios. J. Dairy Sci. 98:418-430. https://doi.org/10.3168/jds.2014-8298.

Barret, M., N. Gagnon, B. Morissette, E. Topp, M. Kalmokoff, S. P. J. Brooks, F. Matias, D. I. Massé, L. Masse, and G. Talbot. 2012. Methanoculleus spp. as a biomarker of methanogenic activity in swine manure storage tanks. FEMS Microbiol. Ecol. 80:427-440. https://doi.org/10.1111/j.1574-6941.2012.01308.x.

Barret, M., N. Gagnon, E. Topp, L. Masse, D. I. Massé, and G. Talbot. 2013. Physico-chemical characteristics and methanogen communities in swine and dairy manure storage tanks: Spatio-temporal variations and impact on methanogenic activity. Water Res. 47:737-746. https://doi.org/10.1016/j.watres.2012.10.047.

Beauchemin, K., T. A. McAllister, and S. McGinn. 2009. Dietary mitigation of enteric methane from cattle. Perspect. Agric. Vet. Sci. Nutr. Nat. Resour. 35:1-18. https://doi.org/10.1079/ PAVSNNR20094035.

Benchaar, C., F. Hassanat, R. Martineau, and R. Gervais. 2015. Linseed oil supplementation to dairy cows fed red clover silage- or corn silage-based diets: Effects on methane production, rumen fermentation, nutrient digestibility, $\mathrm{N}$ balance, and milk production. J. Dairy Sci. 98:7993-8008. https://doi.org/10.3168/jds.2015 -9398 .

Brask, M., P. Lund, A. L. F. Hellwing, M. Poulsen, and M. R. Weisbjerg. 2013. Enteric methane production, digestibility and rumen fermentation in dairy cows fed different forages with and without rapeseed fat supplementation. Anim. Feed Sci. Technol. 184:67-79. https://doi.org/10.1016/j.anifeedsci.2013.06.006.

Broderick, G. A., A. F. Brito, and J. J. O. Colmenero. 2007. Effects of feeding formate-treated alfalfa silage or red clover silage on the production of lactating dairy cows. J. Dairy Sci. 90:1378-1391. https://doi.org/10.3168/jds.S0022-0302(07)71624-7.

CCAC (Canadian Council on Animal Care). 2009. CCAC guidelines on: the care and use of farm animals in research, teaching and testing. Canadian Council on Animal Care, Ottawa, ON, Canada.

Chadwick, D., S. Sommer, R. Thorman, D. Fangueiro, L. Cardenas, B. Amon, and T. Misselbrook. 2011. Manure management: Implications for greenhouse gas emissions. Anim. Feed Sci. Technol. 166167:514-531. https://doi.org/10.1016/j.anifeedsci.2011.04.036.

Demirel, B., and P. Scherer. 2008. The roles of acetotrophic and hydrogenotrophic methanogens during anaerobic conversion of biomass to methane: A review. Rev. Environ. Sci. Biotechnol. 7:173190. https://doi.org/10.1007/s11157-008-9131-1.

Dennehy, C., P. G. Lawlor, T. Croize, Y. Jiang, L. Morrison, G. E. Gardiner, and X. Zhan. 2016. Synergism and effect of high initial volatile fatty acid concentrations during food waste and pig manure anaerobic co-digestion. Waste Manag. 56:173-180. https:// doi.org/10.1016/j.wasman.2016.06.032.

Doreau, M., A. Ferlay, Y. Rochette, and C. Martin. 2014. Effects of dehydrated lucerne and soya bean meal on milk production and composition, nutrient digestion, and methane and nitrogen losses in dairy cows receiving two different forages. Animal 8:420-430. https://doi.org/10.1017/S1751731113002206.

Environment Canada. 2015. Greenhouse Gas Sources and Sinks in Canada, National Inventory Report 1990-2013 Part 2. Environment Canada, Ottawa, ON, Canada.

Environment Canada. 2018. National Inventory Report 1990-2016: Greenhouse Gas Sources and Sinks in Canada-Executive Summary. Environment Canada, Ottawa, ON, Canada.

Hales, K. E., N. A. Cole, and V. H. Varel. 2012. Effects of corn processing method and dietary inclusion of corn wet distillers grains 
with solubles on odor and gas production in cattle manure. J. Anim. Sci. 90:3988-4000. https://doi.org/10.2527/jas.2011-4679.

Hassanat, F., R. Gervais, C. Julien, P. Y. Chouinard, D. I. Massé, A. Lettat, H. V. Petit, and C. Benchaar. 2013. Replacing alfalfa silage with corn silage in dairy cow diets: Effects on enteric methane production, ruminal fermentation, digestion, $\mathrm{N}$ balance, and milk production. J. Dairy Sci. 96:4553-4567. https://doi.org/10.3168/ jds.2012-6480.

IPCC (Intergovernmental Panel on Climate Change). 2006. Emissions from livestock and manure management. In Guidelines for Green House Inventories. Vol. 4. Intergovernmental Panel on Climate Change (IPCC), Geneva, Switzerland.

Külling, D. R., F. Dohme, H. Menzi, F. Sutter, P. Lischer, and M. Kreuzer. 2002. Methane emissions of differently fed dairy cows and corresponding methane and nitrogen emissions from their manure during storage. Environ. Monit. Assess. 79:129-150. https://doi .org/10.1023/a:1020248700255.

Lu, X., H. Wang, F. Ma, G. Zhao, and S. Wang. 2017. Enhanced anaerobic digestion of cow manure and rice straw by the supplementation of an iron oxide-zeolite system. Energy Fuels 31:599-606. https://doi.org/10.1021/acs.energyfuels.6b02244.

Massé, D. I., G. Jarret, C. Benchaar, and F. Hassanat. 2014. Effects of adding corn dried distiller grains with solubles (DDGS) to the dairy cow diet and effects of bedding in dairy cow slurry on fugitive methane emissions. Animals (Basel) 4:767-778. https://doi .org/10.3390/ani4040767.

Massé, D. I., G. Jarret, F. Hassanat, C. Benchaar, and N. M. C. Saady 2016. Effect of increasing levels of corn silage in an alfalfa-based dairy cow diet and of manure management practices on manure fugitive methane emissions. Agric. Ecosyst. Environ. 221:109-114. https://doi.org/10.1016/j.agee.2016.01.018.

Massé, D. I., L. Masse, S. Claveau, C. Benchaar, and O. Thomas. 2008. Methane emissions from manure storages. Trans. ASABE 51:1775-1781. https://doi.org/10.13031/2013.25311.

Massé, D. I., and N. M. C. Saady. 2015. High rate psychrophilic anaerobic digestion of undiluted dairy cow feces. Bioresour. Technol. 187:128-135. https://doi.org/10.1016/j.biortech.2015.03.110.

Molinuevo-Salces, B., X. Gómez, A. Morán, and M. C. GarcíaGonzález. 2013. Anaerobic co-digestion of livestock and vegetable processing wastes: Fibre degradation and digestate stability. Waste
Manag. 33:1332-1338. https://doi.org/10.1016/j.wasman.2013.02 .021 .

Møller, H. B., V. Moset, M. Brask, M. R. Weisbjerg, and P. Lund. 2014. Feces composition and manure derived methane yield from dairy cows: Influence of diet with focus on fat supplement and roughage type. Atmos. Environ. 94:36-43. https://doi.org/10 .1016/j.atmosenv.2014.05.009.

Petersen, S. O. 2018. Greenhouse gas emissions from liquid dairy manure: Prediction and mitigation. J. Dairy Sci. 101:6642-6654. https://doi.org/10.3168/jds.2017-13301.

Pind, P. F.. I. Angelidaki, and B. K. Ahring. 2003. Dynamics of the anaerobic process: Effects of volatile fatty acids. Biotechnol. Bioeng. 82:791-801. https://doi.org/10.1002/bit.10628.

Powell, J. M., G. A. Broderick, J. H. Grabber, and U. C. Hymes-Fecht. 2009. Technical note: Effects of forage protein-binding polyphenols on chemistry of dairy excreta. J. Dairy Sci. 92:1765-1769. https:/ /doi.org/10.3168/jds.2008-1738.

Stinson, J. A., and R. K. Ham. 1995. Effect of lignin on the anaerobic decomposition of cellulose as determined through the use of a biochemical methane potential method. Environ. Sci. Technol. 29:2305-2310. https://doi.org/10.1021/es00009a023.

Van Soest, P. J., J. B. Robertson, and B. A. Lewis. 1991. Methods for dietary fiber, neutral detergent fiber, and nonstarch polysaccharides in relation to animal nutrition. J. Dairy Sci. 74:3583-3597. https://doi.org/10.3168/jds.S0022-0302(91)78551-2.

VanderZaag, A. C., H. Baldéa, A. Crollab, R. J. Gordonc, N. M. Ngwabiea, C. Wagner-Riddlee, R. Desjardins, and J. D. MacDonald. 2018. Potential methane emission reductions for two manure treatment technologies. Environ. Technol. 39:851-858. https://doi.org/ 10.1080/09593330.2017.1313317.

Weatherburn, M. 1967. Phenol-hypochlorite reaction for determination of ammonia. Anal. Chem. 28:971-974. https://doi.org/10 $.1021 / \mathrm{ac} 60252 \mathrm{a} 045$.

\section{ORCIDS}

F. Hassanat (1) https://orcid.org/0000-0002-2311-8234

C. Benchaar (1) https://orcid.org/0000-0002-8644-6892 